\title{
THE POTENTIAL OF BIOCHEMISTRY EDUCATION APPS IN THE FORMATIVE ASSESSMENT
}

\author{
Mayara Lustosa de Oliveira, Thanuci Silva, Juan Carlos Vega Garzón, \\ Eduardo Galembeck.
}

\section{Department of Biochemistry and Tissue Biology, Institute of Biology, State University of Campinas (UNICAMP). Campinas, Sao Paulo, Brazil. Phone: 55 (19) 3521-6653, e-mail: mayarabioufg@gmail.com.}

Introduction and objectives: Apps can be designed to provide usage data, and most of them do. These data are usually used to map users interests and to deliver more effective ads that are more likely to result in clicks, and sales. We have applied some of these metrics to understand how can it be used to map students' behavior and to promote a formative assessment using educational software. The purpose of a formative assessment is to monitor student learning to provide ongoing feedback that can be used by instructors and students to improve the teaching and learning process. Thus, this modality aims to help both students and instructors to identify strengths and weaknesses that need to be developed. This study aimed to describe the potential of educational apps in the formative assessment process. Material and Methods: We have implemented assessment tools embedded in three apps (ARMET, The Cell and 3D Class) used to teach: 1) Metabolic Pathways; 2) Scale of the cellular structures, and 3) Concepts from techniques used in a Biochemistry Lab course. The implemented tools allow to verify on what issues there were recurring mistakes, the total number of mistakes presented, which questions they most achieved, how long they took to perform the activity and other relevant information. Results and conclusion: Educational apps can provide transparent and coherent evaluation metrics to enable instructors to systematize more consistent criteria and indicators, reducing the subjectivity of the formative assessment process and the time spent for preparation, tabulation and analysis of assessment data. This approach allows instructors to understand better where students struggle, giving to them a more effective feedback. It also helps instructor to plan interventions to help students to perform better and to achieve the learning objectives.

Key Words: Formative Assessment, Educational Apps, Biochemistry. 